\title{
Characteristics Analysis of Urban Space Expansion in Luoyang, China
}

\author{
Kaiguang Zhang, Hongling Meng, Mingting Ba, Yanmin Sun \\ School of Geography and Tourism, Zhengzhou Normal University, Zhengzhou, China \\ Email: zzgis@zznu.edu.cn
}

How to cite this paper: Zhang, K. G., Meng, H. L., Ba, M. T., \& Sun, Y. M. (2022). Characteristics Analysis of Urban Space Expansion in Luoyang, China. Journal of Geoscience and Environment Protection, 10, 123-139. https://doi.org/10.4236/gep.2022.101009

Received: December 20, 2021

Accepted: January 16, 2022

Published: January 19, 2022

Copyright $\odot 2022$ by author(s) and Scientific Research Publishing Inc. This work is licensed under the Creative Commons Attribution International License (CC BY 4.0).

http://creativecommons.org/licenses/by/4.0/

\begin{abstract}
The characteristics of urban space expansion reflect the changes of urban space layout and space structure, as well as the urban developing direction and urban orientation in the future. Based on the remote sensing image data of 1990, 2000, 2010 and 2020, this paper analyzes the urban space expansion characteristics of Luoyang, by using the urban land compaction index, expansion intensity index and centroid distribution in 4 time sections and 3 periods. The results show that: 1) the urban land area of Luoyang has expanded rapidly, the urban planning policy has successfully guided the urban expansion. 2) In the first period, the urban expansion belongs to the rapid expansion type, mainly filling the built-up area and natural expansion to outward; the second period is of high-speed expansion type, the urban expansion mainly enlarges the urban framework, then fills the expanded district, and the influence of urban natural growth factor is very small; the third period belongs to the high-speed expansion type, and the expansion rate is significantly lower than that in the second period, the urban expansion is mainly to fill in the urban framework enlarged in the previous period and continue to enlarge the urban framework, and the influence of urban natural growth factor is very little. 3) The urban land centroid gradually migrates to the southeast with the azimuth of $151.47^{\circ}$, the annual migration distance is of $138.29 \mathrm{~m}$. The migration rate in the second period is the fastest, which is about 7.43 times that of the first period, and 2.70 times that of the third period. In the first period, the urban land is mainly expanded to southward, with the main azimuth of $201.13^{\circ}$. Compared with the urban land centroid in 2000, the urban land in the second period mainly expands to east-southeast and southward along the azimuths of $141.92^{\circ}$ and $154.17^{\circ}$ respectively. Compared with the urban centroid in 2010, the urban land in the third period mainly expands in the orientations of southeast and eastward along the azimuth of $96.24^{\circ}$ and $133.45^{\circ}$.
\end{abstract}

\section{Keywords}

Urban Space Expansion, Compaction Index, Expand Intensity Index, Expand 


\section{Introduction}

Urban space expansion is a comprehensive reflection of the changes of spatial layout and structure in the process of urbanization, is a dynamic process of the interaction between internal and external factors of the urban, including the expansion of urban geographic space and the optimization and adjustment of urban internal structure (Yan \& Huang, 2013, Yu \& Chen, 2020, Wang et al., 2014). The formation and expansion of urban have geographical and temporal characteristics, which are affected by regional natural conditions, macro social background, economic development status, urban planning strategies, and other factors. In time, they show the characteristics of stages and sequence. In space, they show the changes of urban spatial pattern (Wang et al., 2014, Lu, 2020).

In recent years, with the rapid development of China's economy, the urbanization rate has been continuing to increase, and the urban land area has gradually been expanding. There is a certain positive correlation between the degree of urban space expansion and urban economic development, but there are obvious regional characteristics (Tang et al., 2017).

The development of urban economy and the increase of non-agricultural population should inevitably lead to the demand of urban for construction land, resulting in a decrease of cultivated land in the surrounding area. With ensuring the rapid development of urban economy, how to achieve reasonable urban space expansion and adjustment of urban internal structure is one of the main problems faced by Chinese urbans (Ge et al., 2000, Chang \& Li, 2017).

Studying the history of urban space expansion and analyzing the characteristics of space expansion have important guiding significance for analyzing and predicting the changing trend of urban space expansion, formulating urban regional planning and overall planning, improving the level of urban management, and promoting urban economic development (Ge et al., 2000, Geng et al., 2019, Xiong et al., 2016, Huang et al., 2018, Li et al., 2017).

Luoyang, a famous historical and cultural city, as the economic development of the sub-central city of the Central Plains Economic Zone, plays an important leading role in the development of the western region of the economic zone. Luoyang's regional plan and overall planning take the change of urban expansion spatial pattern as an important basic research for the new planning formulation. The research is to understand the changes of urban spatial layout and urban structure in the process of urbanization, so as to realize the construction of urban and the protection of famous historical and cultural city, the control of urban development intensity, the optimization of urban space structure, and compact and intensive development (Ge et al., 2000, Xiong et al., 2016, Zhao et al., 2019). 


\section{Data and Research Methods}

\subsection{Research Area Overview}

Luoyang urban $\left(34^{\circ} 30^{\prime} \mathrm{N}-34^{\circ} 46^{\prime} \mathrm{N}, 112^{\circ} 15^{\prime} \mathrm{E}-112^{\circ} 38^{\prime} \mathrm{E}\right)$ is located in the west of Henan province, the transition zone between the third and second steps of China's terrain, on the platform of Luo River (with an average width of $500 \mathrm{~m}$ ), Yi River (with an average width of $600 \mathrm{~m}$ ), Jian River and Chan River, where belongs to the western region of Henan and the eastern Qinling Mountains fold system, with the average elevation of $200 \mathrm{~m}$ and the maximum elevation difference of $740 \mathrm{~m}$. The north, west and south are respectively covered by Mang Mountains, Qinling Mountains (Mount Zhou) and Mount Longmen, forming Luoyang basin (as shown in Figure 1).

Luoyang urban has a civilization history of more than 5000 years, more than 4000 years of history as a urban, and more than 1500 years of history as a capital. In history, thirteen dynasties established their capitals in here. At present, there are two major urban sites in the built-up area, as Chengzhou City and King City of Eastern Zhou Dynasty Remains, and Sui and Tang City Remains.

In 1046 B.C., in order to rule the eastern region, the successors of Western Zhou Dynasty began to build a new national capital, Chengzhou City, on the north side of Luo River and the east and west sides of Jian River. The built-up area is of about $12.45 \mathrm{~km}^{2}$ (Figure 1). In 770 B.B., DongPing king moved his capital east to Luoyi, built Dongzhou King City on both sides of Jian River, covering an area of about $9 \mathrm{~km}^{2}$ (Liu \& Song, 1997, Cai et al., 2013) (Figure 1). In

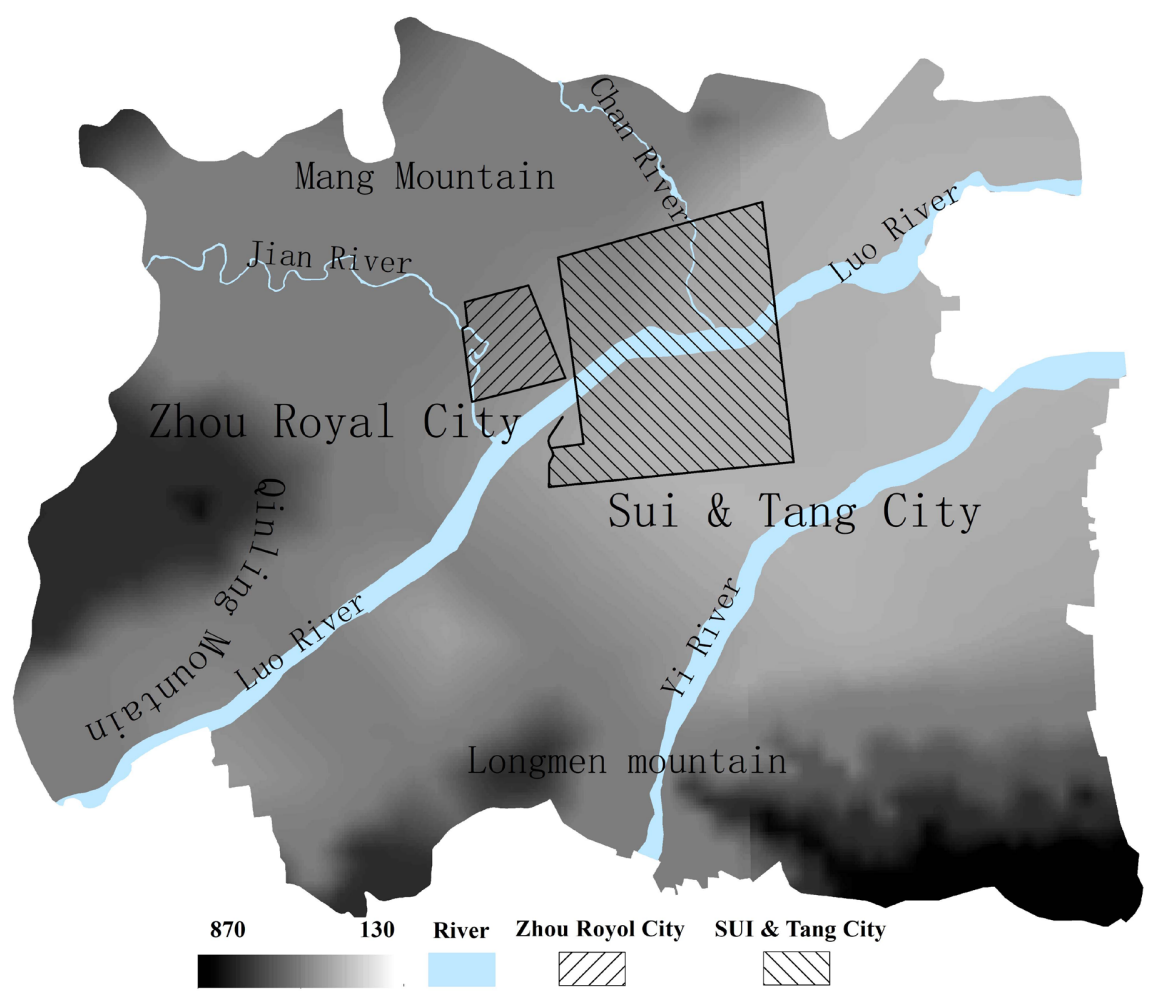

Figure 1. Luoyang ancient city distribution. 
605, Sui Dynasty began to build a urban on both sides of the Luo River, where continued to be constructed and improved by Tang Dynasty, formed Sui and Tang City with the area of $47 \mathrm{~km}^{2}$. It is the first time, the Chinese capital construct crossed large rivers, which could provide favorable conditions for urban water supply and drainage, water transportation, commercial trade, and forming the prototype of modern urban function (Liu \& Song, 1997, Cai et al., 2013).

In 1953, Luoyang began to compile and implement the first phase of Luoyang overall planning, avoid the old urban area, and make overall arrangements for the production of national key construction projects, staff life, external transportation and urban infrastructure construction, in order to transform a consumption urban into an industrial production urban, and focus on the implementation of the Jianxi industrial zone planning and Jiandong planning (Liu \& Song, 1997).

In 1981, the second phase of Luoyang overall planning was prepared and implemented. Based on the current situation, the planning adjusted the urban the structure, filled and improved regional function, in order to constructe a clean and beautiful, economically coordinated industrial urban with the characteristics of an ancient capital. The urban construction developed toward Qinling Mountains in the west, toward north side of Luo River in the middle, improved and filled the parts not implemented in the first phase overall planning, enrich suburban industrial sites and build satellite towns in the east, did not develop toward Mang Mountains in the north and the south side of Luo River in the south (Liu \& Song, 1997).

In 1997, the third phase of Luoyang overall planning, was prepared and implemented. The urban development crossed Longhai railway to the north to form Mang Mountains Group, constructed a high-tech industrial zone in the southwest, crossed Luo River and stride over Sui and Tang City Remains to the south, improved Guanlin group, and developed Luonan west group in the long term. Retained Xigong commercial center and moved the urban administrative center to the south, with the Luo River as the axis, the two sides develop symmetrically to form a banded group layout.

In 2008, the fourth phase of Luoyang overall planning has been prepared and implemented, The urban construction focused on extending to north and west, enriched Luonan New District, taped the land potential in the north side of Luo River, starting the construction of area on the south side of Yi River, and took the north of Mang Mountains tombs group as the future urban development space.

\subsection{Data and Processing}

The data used in this study mainly include $10 \times 10$ DEM data and Luoyang traffic network and administrative division data coming from Henan basic geographic information database and meta database, the urban planning data of Luoyang coming from the geospatial database and meta database of Luoyang geographic information center, the remote sensing image data of land use status 
coming from June to July in the four periods of 1990, 2000, 2010 and 2020 with the resolution of $9.87 \mathrm{~m}$ and the accuracy of more than $95 \%$, coming from geospatial data cloud (http://www.gscloud.cn/). According to the land use and time series characteristics of the study area, the urban land is manually interpreted. The results of manual interpretation in 2020 are randomly sampled in the urban-rural fringe, the total of 20 samples with the sample size $20 \times 20 \mathrm{~m}$ are selected, their statistical analysis shows that the average error is less than $1 \%$. The interpreted urban land area in the other three years compare with the built-up area data in the statistical yearbook of Luoyang in the corresponding year, the error less than 3\%. Therefore, the later research on the urban expansion model and the exploration of the expansion direction are mainly base on the urban land interpreted data.

\subsection{Research Methods}

Urban spatial expansion is mainly reflected in the continuous expansion of urban space. The purpose of urban space expansion research is to study the spatial temporal characteristics of urban spatial layout, expansion speed and expansion direction, and analyze and predict the change trend of urban expansion.

\subsubsection{Compaction Index}

The compaction of urban space (Tang et al., 2017, Lu, 2020) is an important indicator to describe the urban space form, reflects the degree of close relationship between various regions within the city, and the utilization efficiency of urban land and infrastructure (Tang et al., 2017). As the closest relationship between points in a unit area is a circle, so the compaction $C_{i}$ of a map spot of land $i$ is defined as the normalized value of the ratio of area $A_{i}$ to perimeter $P_{i}$

$$
C_{i}=\frac{2 \sqrt{\pi A_{i}}}{P_{i}}
$$

The urban space compaction $C$ is defined as the weighted average of the map spot of land with area as weight

$$
C=\frac{\sum_{i=1}^{n} A_{i} C_{i}}{\sum_{i=1}^{n} A_{i}}
$$

where $n$ is the number of map spots in the city. $C_{i}$ and $C$ belongs to $(0,1]$. As a map spot is close to a circular, it reaches the maximum value of 1 , the shape of a map spot tends to be narrow and long, its value tends to $0 . C$ tends to 1 indicates that the more compaction the urban land, the closer the internal space, and the higher land use efficiency; $C$ tends to 0 indicates that the worse compaction, the looser the interior, more undeveloped areas, and the lower the urban land use efficiency (Tang et al., 2017, Lu, 2020).

\subsubsection{Expand Intensity Index}

The expand intensity index (Yu \& Chen, 2020, Lu, 2020) is used to analyze and describe the state of urban space expansion, is defined as the proportion of ur- 
ban land expansion area to the base period area in a certain period of time, which represents the relative (proportional) difference in the expansion speed of different regions in a unit time. The expand intensity index of a map spot of land $i$ defined as

$$
N_{i}=\frac{\Delta U_{i j}}{\Delta t_{j} M_{i}} \times 100 \%
$$

where, $\Delta U_{i j}$ is the expansion area of $i$ during the period $j, \Delta t_{j}$ is the time span of the period $j, M_{i}$ is the urban land area in the base period of $j$.

\subsubsection{Centroid Migration Model}

The regional spatial distribution centroid $\left(X_{i}, Y_{i}\right)$ of a map spot of land $i$ represents the central position of regional spatial distribution (Zhang et al., 2017, $\mathrm{Lu}, 2020$ ), defined as the weighted average of the centroid coordinates of each map spot of land in the region $i$ with area as the weight

$$
X_{i}=\frac{\sum_{k=1}^{n} X_{i k} A_{k}}{\sum_{k=1}^{n} A_{k}}, \quad Y_{i}=\frac{\sum_{k=1}^{n} Y_{i k} A_{k}}{\sum_{k=1}^{n} A_{k}}
$$

where, $n$ is the number of map spot of land in the region, $\left(X_{i k}, Y_{i k}\right)$ and $A_{k}$ respectively the centroid coordinates and the area of the map spot of land in the region. The change of centroid position reflects the direction and speed of urban space expansion.

\section{The Characteristics Analysis of Urban Space Expansion in Luoyang}

\subsection{The Urban Morphology Evolution Analysis in Luoyang}

The urban space compaction describes the urban space morphology, the degree of close relationship between various regions within the city, the utilization efficiency of urban land and infrastructure, and the periodicity of urban expansion (Tang et al., 2017). As the city expands rapidly and the internal land is not fully developed, the urban space compaction decreases. As the urban construction shifts to internal reconstruction and regional filling, the urban space compaction increases.

The remote sensing images of four years (as 1990, 2000, 2010 and 2020) are interpreted manually, and the results are shown in Figures 2-5. Using Equation (1) to calculate the urban space compaction of each year, the results are shown in Table 1. Overall, all of the urban space compaction of Luoyang in the four years is not high, but there are significant differences in the causes.

Restricted by topographic conditions, in 1990, the city was mainly distributed in the narrow area north of Luo River and south of Mang Mountains showing an "L" shape. From 1990 to 2000, due to the limitations of topographic conditions and Longhai Railway on the foot of Mang Mountains, the city development mainly is the filling type. The land in the urban section north of Luo River is 


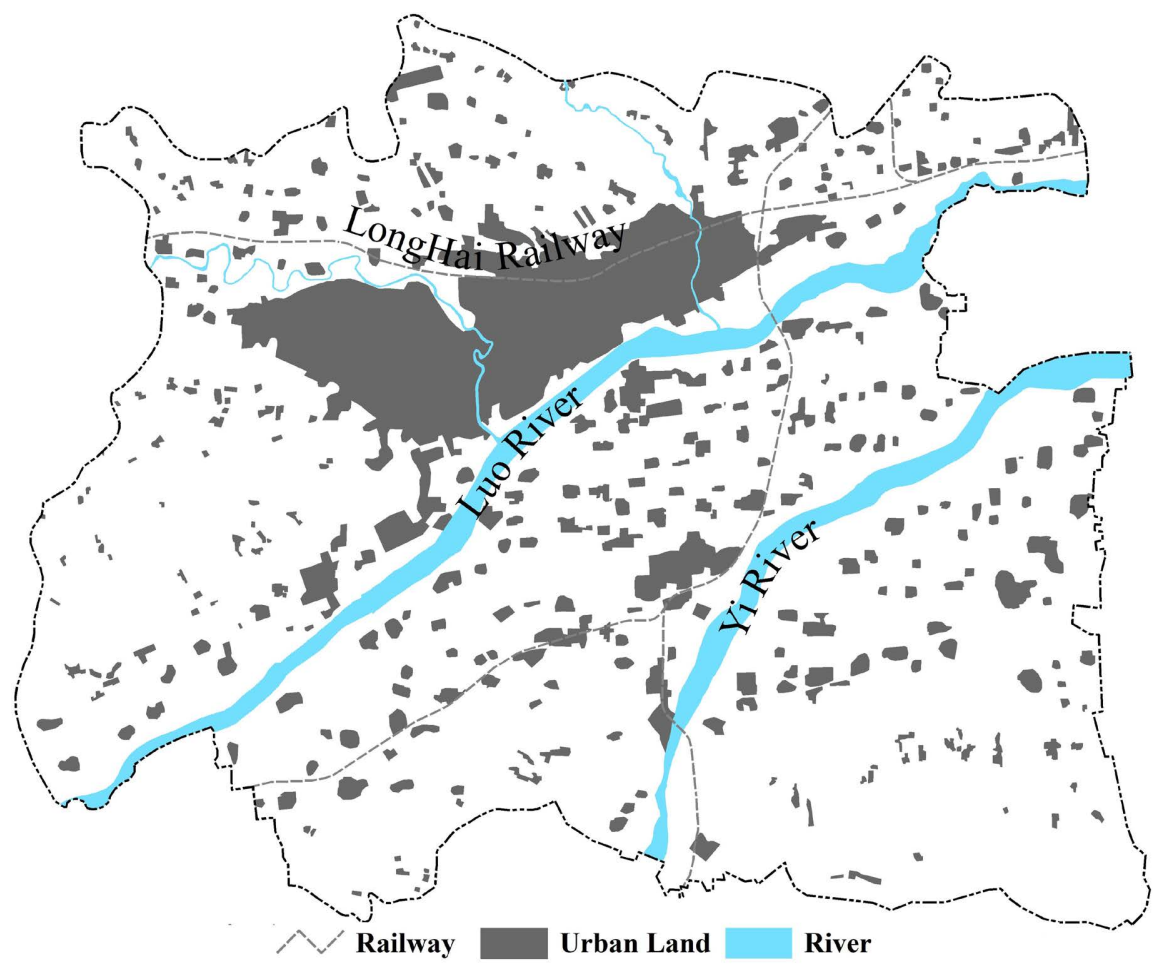

Figure 2. Luoyang urban land in 1990.

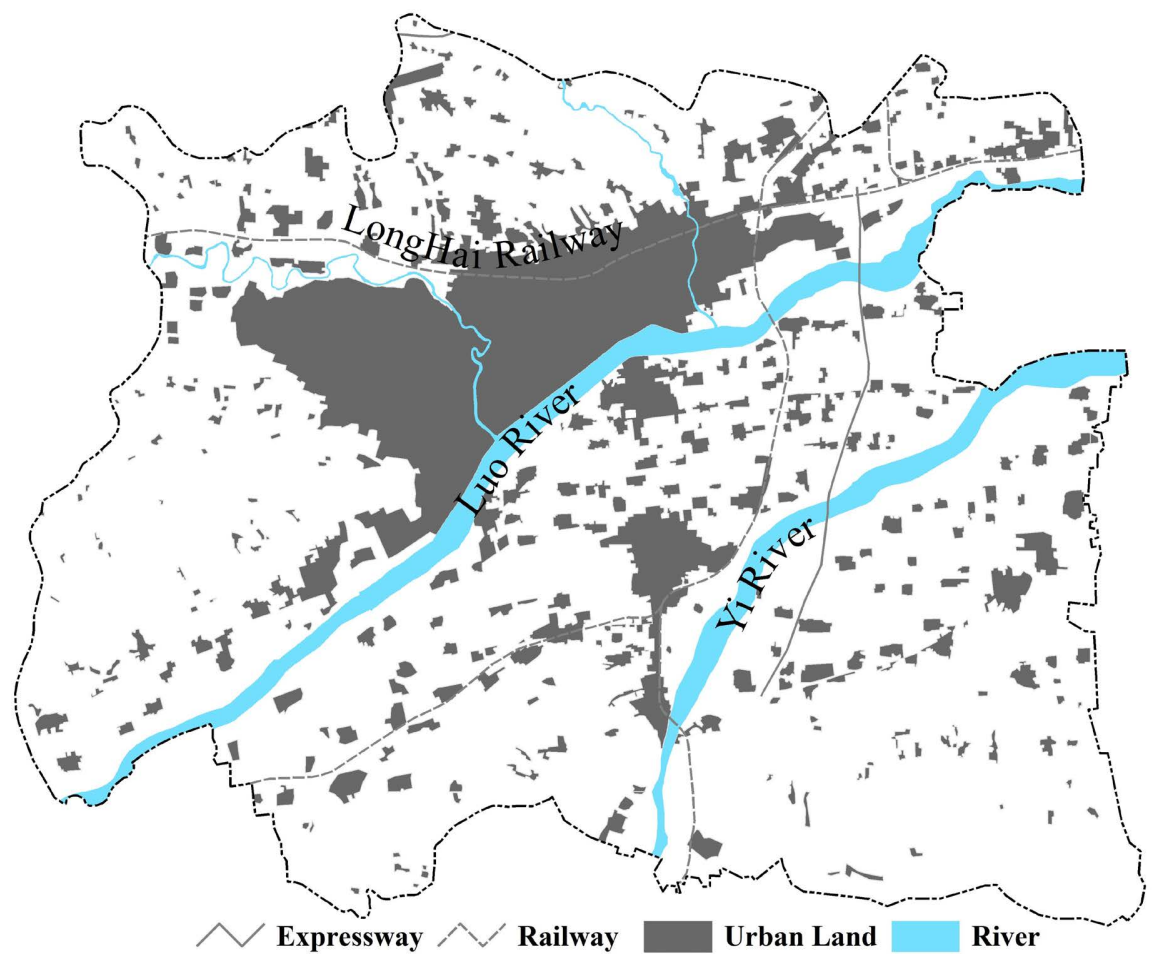

Figure 3. Luoyang urban land in 2000.

basically filled. Due to the complex topography, the L-shaped concave part keeps basically unchanged, the narrowness of the city further increases, resulting in a decrease in the urban space compaction. 


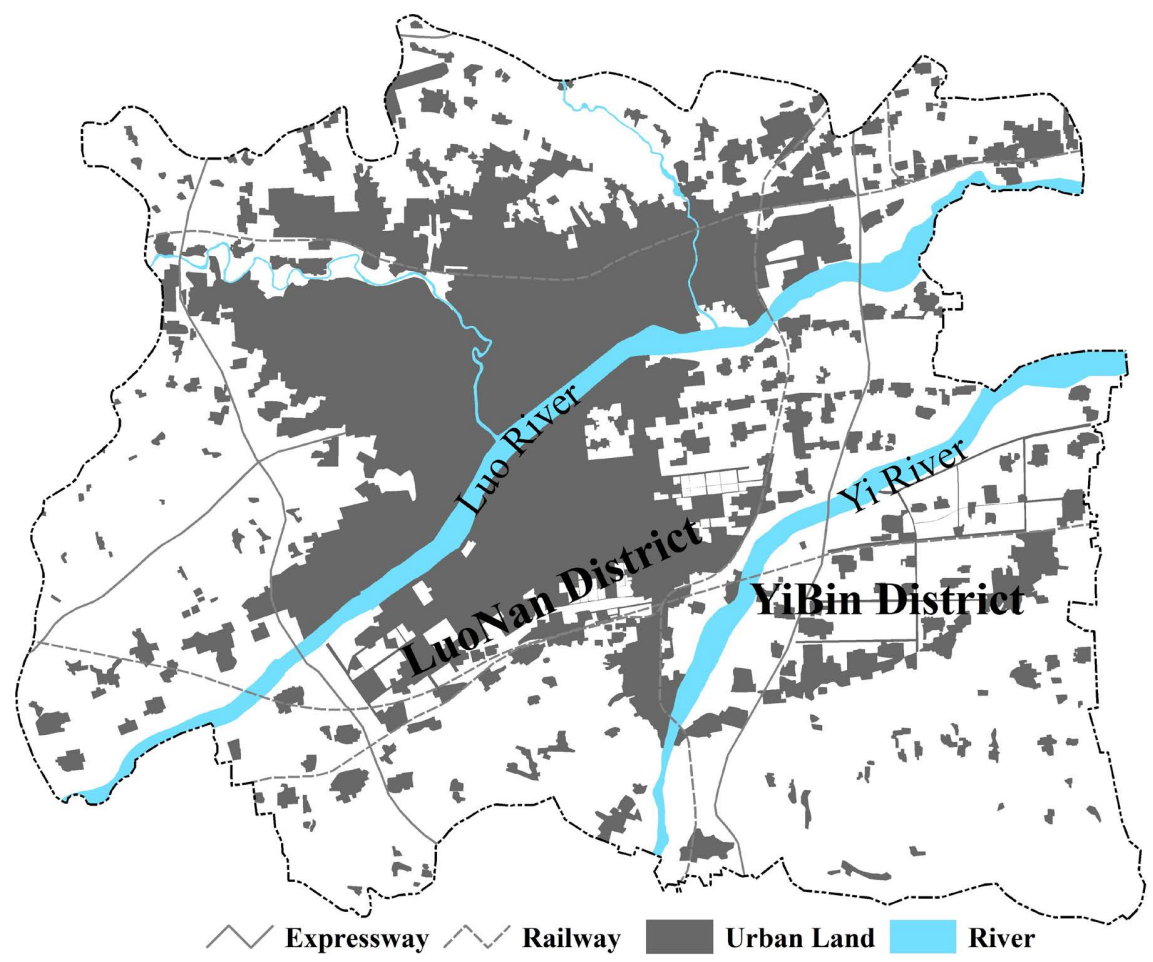

Figure 4. Luoyang urban land in 2010.

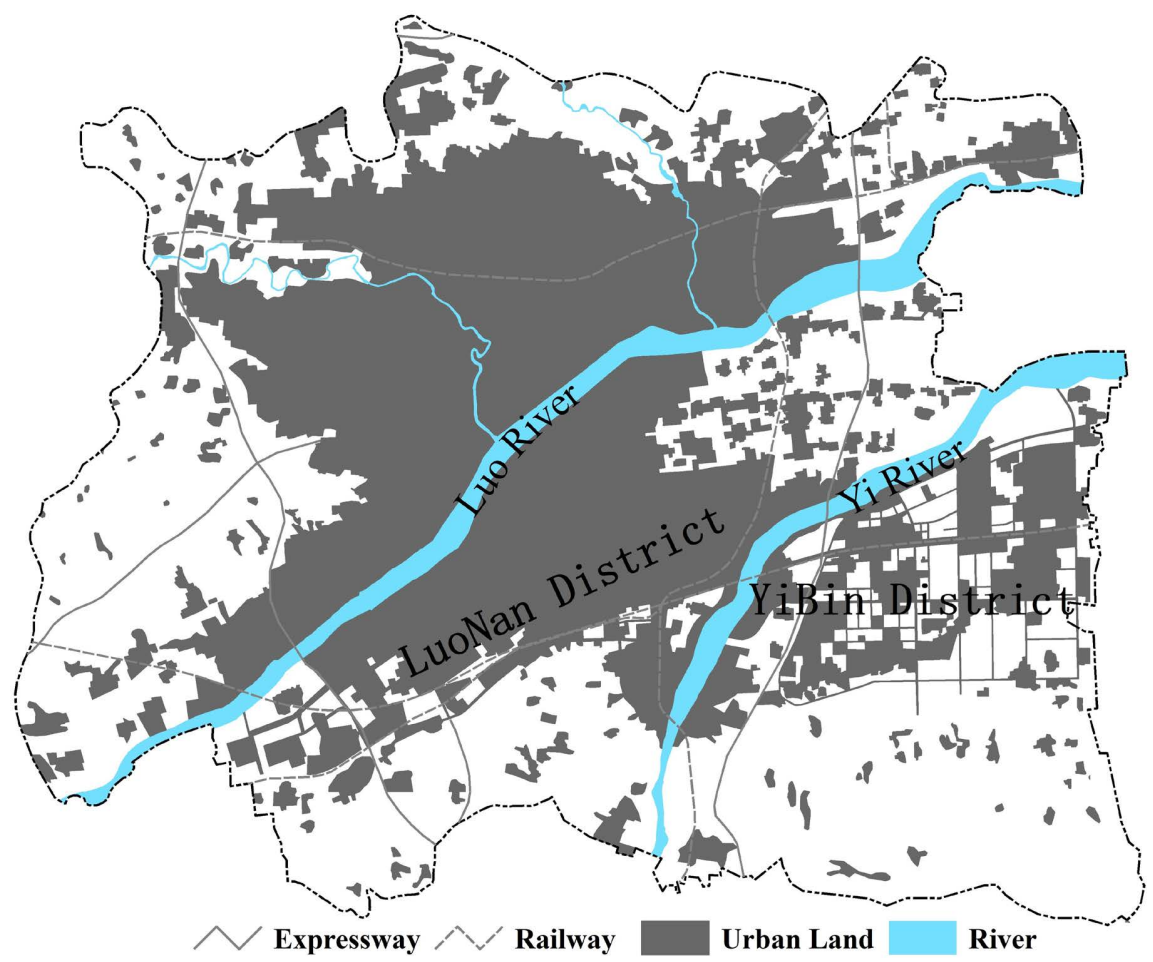

Figure 5. Luoyang urban land in 2020.

From 2000 to 2010, the urban development crosses Longhai Railway to Mang Mountains in the north, and the L-shaped concave part is filled to a certain extent, with small urban narrowness expansion, which make the urban space compaction 
Table 1. The distribution characteristics of Luoyang urban land (1990-2020).

\begin{tabular}{ccccc}
\hline Year & $\begin{array}{c}\text { Urban Land Area } \\
\left(\mathrm{km}^{2}\right)\end{array}$ & Compaction Index & $\begin{array}{c}\text { Expansion Rate } \\
\left(\mathrm{km}^{2} / \mathrm{a}\right)\end{array}$ & $\begin{array}{c}\text { Expand Intensity } \\
\text { Index }\end{array}$ \\
\hline 1990 & 54.55 & 0.35 & - & - \\
2000 & 71.51 & 0.29 & 1.70 & 3.11 \\
2010 & 172.50 & 0.18 & 10.10 & 14.12 \\
2020 & 259.89 & 0.31 & 8.74 & 5.07 \\
\hline
\end{tabular}

increases in the north of Luo River. However, with the development of the urban across Luo River to the south, the urban framework expands rapidly, and the new development district is not effectively filled, which further reduces the urban space compaction of the whole urban.

From 2010 to 2020, in the built-up area in the north of the Luo River, the filling of the L-shaped concave part is basically completed, and the urban development continues to expand to the north. Except for the south restricted by Luo River, the outward expansion intensity of other directions are basically the same. the urban space compaction of the region has been greatly improved. At the same time, the newly built area in the south of the Luo River also has been effectively filled, which has significant improved the overall urban space compaction of the whole city. However, the perfect road network and imperfect land filling in Yibin New District, located in the south of Yi River, makes the urban space compaction of the whole city significant decreases.

\subsection{The urban Expansion Characteristics Analysis in Luoyang}

For the interpretation results of remote sensing images in four years, using Equation (2) and Equation (3) to calculate the urban land areas, annual expansion rates and expansion intensities in each year. The results are shown in Table 1. From the perspective of expansion area, the urban expansion mode of Luoyang is the rapid expansion type and high-speed expansion type ( $\mathrm{Lu}, 2020)$. From 1990 to 2000, the urban expansion area, expansion rate and expansion intensity are far less than those in the other two periods, which is largely related to the urban development planning at that time and the development policy focus during this decade.

During 1990-2000, affected by the urban economic conditions, topographic factors and the second phase of urban overall planning, the urban development mainly fills the north of Luo River and the south of Longhai railway, with a trend of expanding to the East and West, the built-area increase of $16.96 \mathrm{~km}^{2}$. At the end of this period, due to the needs of urban economic development and population growth, the third phase of the urban overall planning begin to compile and implement.

From 2000 to 2010, the urban expansion mode is rapid expansion type, and the urban expansion area, expansion rate and expansion intensity are greater than those in the other two periods. The urban crosses Luo River and strides 
over Sui and Tang Dynasties Remains to the south, Sui and Tang Dynasties Remains and the remains protection region are incorporated into the urban land in the form of urban parks and green spaces to form Luonan New District, where the construction of the urban framework has been completed, and partial filling was carried out. At the same time, the urban begin to develop across Longhai Railway towards Mang Mountains. The built-up area in 2010 is 2.41 times that in 2000 , an increase of $100.99 \mathrm{~km}^{2}$ to $172.50 \mathrm{~km}^{2}$. At the end of this period, due to the needs of urban economic development, the fourth phase of urban master plan is prepared and implemented.

Compared to the rapid urban expansion in the previous period, from 2010 to 2020, the urban expansion area, expansion rate and expansion intensity are slightly less than those in the second period, but far greater than those in the first period. The urban development continues to fill the urban framework of Luonan New District, develop to Mang Mountains in the north, and begin to expand to the west. The urban built-area increases by $87.39 \mathrm{~km}^{2}$, the expansion intensity is 8.74, slightly less than 10.10 in the second period, is 5.14 times that in the first period. The west of Luonan New District is the ring expressway and Qinling Mountains, the south is the Zhengxi high-speed railway and Mount Longmen, and the north is Sui and Tang Dynasties Remains. All of them have been greatly restricting its regional expansion. Due to the needs of urban economic development and population increase, the urban begin to expand across the Yi River to the southeast, forming Yibin New District, where the framework is basically formed and has been filled to a certain extent.

\subsection{The Expand Orientation Analysis in Luoyang}

For the interpretation results of remote sensing images in four years, use Equation (4) to calculate the urban land centroid and centroid migration orientation in each year. The results are shown in Table 2.

From 1990 to 2020, the urban land centroid has been shifted to the southeast (Figure 6), with an offset axis of $155.93^{\circ}$. The urban land centroids always are located in the north of Luo River. With the development and utilization of Luonan region, by 2010, the urban land centroid moves southward to Luo River, with an azimuth of $157.89^{\circ}$, basically achieving the goal of symmetrical development on both sides with Luo River as the symmetry axis. By 2020, the urban land centroid continues to migrate to the southeast with an azimuth of $132.2^{\circ}$.

Table 2. The centroid distribution of Luoyang urban land (1990-2020).

\begin{tabular}{cccccc}
\hline Year & $\mathrm{X}(\mathrm{m})$ & $\mathrm{Y}(\mathrm{m})$ & $\mathrm{D}(\mathrm{m})$ & $\mathrm{V}(\mathrm{m} / \mathrm{a})$ & Azimuth $\left(\theta^{\circ}\right)$ \\
\hline 1990 & $30,148.85$ & $38,063.96$ & & & \\
2000 & $30,303.01$ & $37,718.79$ & 378.03 & 37.80 & 155.93 \\
2010 & $31,359.53$ & $35,118.08$ & 2807.12 & 280.71 & 157.89 \\
2020 & $32,130.56$ & $34,419.00$ & 1040.77 & 104.08 & 132.2 \\
\hline
\end{tabular}




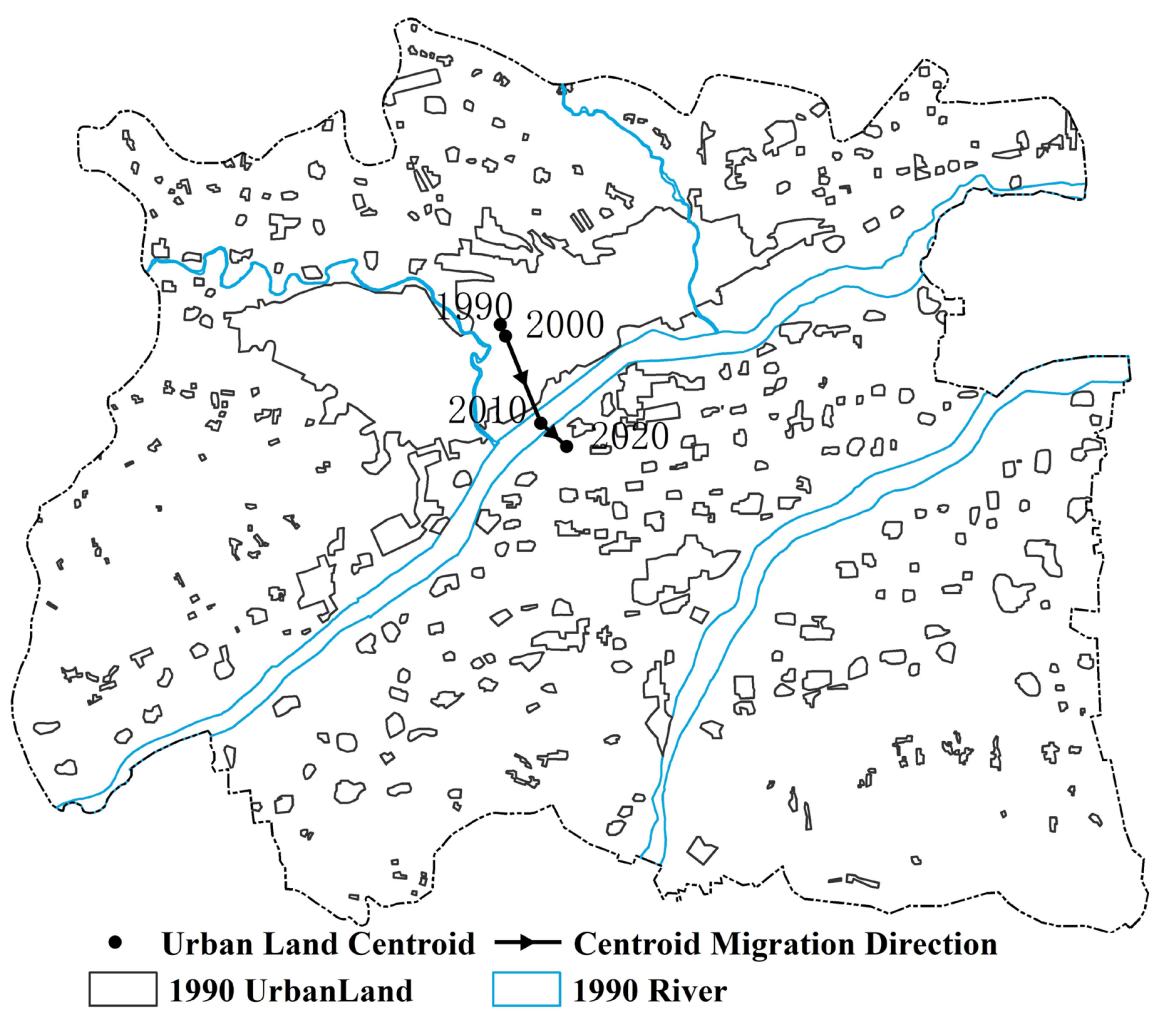

Figure 6. Luoyang urban land centroid distribution.

The centroid migration rates vary greatly in the four periods. The centroid migration rate in the first period is only $37.80 \mathrm{~m} / \mathrm{a}$. In the second period, the centroid migration rate increases by 6.43 times to $280.71 \mathrm{~m} / \mathrm{a}$. In the third period, the centroid migration rate decreases, but it is still 2.75 times that in the first period.

In order to study the expansion intensity and rate of urban land expansion in different directions, taking the urban land centroid of the first year in a period of time as the center, dividing the urban land into 8 fan-shaped areas, which takes north as the starting direction and $22.5^{\circ}$ as the division unit. One urban land expand orientation contains two fan-shaped areas on left and right side of the direction, these expand orientations are named in a clockwise direction. For example, NE (North to East) represents the fan-shaped area with the azimuth angle of $0^{\circ}-45^{\circ}$. Use Equation (3) and Equation (4) to calculate the expansion intensity, centroid and centroid migration direction in each orientation. The results are shown in Tables 3-5.

Compared with the urban land centroid in 1990 (Table 3, Figure 7), the distribution of the urban land centroid in the 8 orientations show some different characteristics in 2000. Due to the reduction of the zoning, the urban space compaction of all zone have changed, the urban space compaction of $\mathrm{WN}$ and $\mathrm{NN}$ are two less than the overall urban space compaction, the urban space compaction of SS and SW are much higher than the overall urban space compaction.

The largest areas of urban expansion are in SW and SS orientation, and the 
Table 3. The distribution of the partition centroids in 2000 based on the urban land of 1990.

\begin{tabular}{lcccccccc}
\hline & $\mathrm{NN}$ & $\mathrm{NE}$ & $\mathrm{EE}$ & $\mathrm{ES}$ & $\mathrm{SS}$ & $\mathrm{SW}$ & $\mathrm{WW}$ & $\mathrm{WN}$ \\
\hline Urban Land $(1990)\left(\mathrm{km}^{2}\right)$ & 4.32 & 19.76 & 21.09 & 6.29 & 8.82 & 20.08 & 20.32 & 8.43 \\
$\mathrm{X}(1990)(\mathrm{km})$ & 30.28 & 34.32 & 34.32 & 31.55 & 29.36 & 27.02 & 26.14 & 26.76 \\
$\mathrm{Y}(1990)(\mathrm{km})$ & 39.54 & 39.66 & 39.29 & 37.05 & 35.89 & 36.51 & 37.42 & 38.78 \\
Urban Land $(2000)\left(\mathrm{km}^{2}\right)$ & 4.99 & 24.60 & 26.65 & 8.12 & 16.43 & 29.03 & 23.44 & 9.76 \\
$\mathrm{X}(2000)(\mathrm{km})$ & 30.38 & 34.92 & 34.88 & 31.84 & 28.91 & 27.15 & 26.06 & 26.79 \\
$\mathrm{Y}(2000)(\mathrm{km})$ & 39.64 & 39.94 & 39.52 & 36.98 & 34.73 & 35.68 & 37.36 & 38.80 \\
D (m) & 141.34 & 658.12 & 609.11 & 297.79 & 1246.15 & 841.70 & 97.69 & 29.99 \\
V (m/a) & 14.13 & 65.81 & 60.91 & 29.78 & 124.62 & 84.17 & 9.77 & 3.00 \\
Azimuth $\left(\theta^{\circ}\right)$ & 42.38 & 64.22 & 68.36 & 104.67 & 201.13 & 171.55 & 234.47 & 59.67 \\
Compaction Index & 42.48 & 27.63 & 33.21 & 61.03 & 59.74 & 55.83 & 64.50 & 40.58 \\
Expansion Rate $\left(\mathrm{km}^{2} / \mathrm{a}\right)$ & 0.07 & 0.48 & 0.56 & 0.18 & 0.76 & 0.90 & 0.31 & 0.13 \\
Expand Intensity Index & 1.56 & 2.45 & 2.63 & 2.91 & 8.64 & 4.46 & 1.53 & 1.58 \\
\hline
\end{tabular}

Table 4. The distribution of the partition centroids in 2010 based on the urban land of 2000 .

\begin{tabular}{|c|c|c|c|c|c|c|c|c|}
\hline & $\mathrm{NN}$ & $\mathrm{NE}$ & $\mathrm{EE}$ & ES & SS & SW & WW & $\mathrm{WN}$ \\
\hline Urban Land (2000) $\left(\mathrm{km}^{2}\right)$ & 6.65 & 26.10 & 25.66 & 5.78 & 14.20 & 26.73 & 25.00 & 12.89 \\
\hline $\mathrm{X}(2000)(\mathrm{km})$ & 30.57 & 34.84 & 35.00 & 31.62 & 28.93 & 27.30 & 26.19 & 26.75 \\
\hline $\mathrm{Y}(2000)(\mathrm{km})$ & 39.52 & 39.81 & 39.50 & 36.74 & 34.50 & 35.46 & 37.24 & 38.61 \\
\hline Urban Land (2010) $\left(\mathrm{km}^{2}\right)$ & 15.84 & 34.37 & 49.46 & 58.64 & 71.45 & 52.53 & 35.76 & 26.96 \\
\hline $\mathrm{X}(2010)(\mathrm{km})$ & 30.23 & 34.95 & 37.10 & 35.32 & 30.48 & 27.07 & 25.68 & 26.53 \\
\hline $\mathrm{Y}(2010)(\mathrm{km})$ & 40.64 & 40.02 & 36.87 & 32.02 & 31.31 & 33.00 & 37.86 & 39.72 \\
\hline $\mathrm{D}(\mathrm{m})$ & 1165.15 & 235.41 & 3360.15 & 5991.43 & 3550.05 & 2465.52 & 800.97 & 1136.83 \\
\hline $\mathrm{V}(\mathrm{m} / \mathrm{a})$ & 116.52 & 23.54 & 336.02 & 599.14 & 355.01 & 246.55 & 80.10 & 113.68 \\
\hline Azimuth $\left(\theta^{\circ}\right)$ & 342.88 & 28.68 & 141.32 & 141.92 & 154.17 & 185.44 & 321.00 & 348.68 \\
\hline Compaction Index & 0.25 & 0.28 & 0.29 & 0.25 & 0.30 & 0.37 & 0.43 & 0.37 \\
\hline Expansion Rate $\left(\mathrm{km}^{2} / \mathrm{a}\right)$ & 0.92 & 0.83 & 2.38 & 5.29 & 5.73 & 2.58 & 1.08 & 1.41 \\
\hline Expand Intensity Index & 13.81 & 3.17 & 9.27 & 91.41 & 40.33 & 9.65 & 4.30 & 10.91 \\
\hline
\end{tabular}

Table 5. The distribution of the partition centroids in 2020 based on the urban land of 2010 .

\begin{tabular}{lcccccccc}
\hline & NN & NE & EE & ES & SS & SW & WW & WN \\
\hline Urban Land (2010) $\left(\mathrm{km}^{2}\right)$ & 41.39 & 37.81 & 39.51 & 42.32 & 40.35 & 39.99 & 51.26 & 52.38 \\
X (2010) $(\mathrm{km})$ & 31.43 & 35.15 & 38.23 & 36.54 & 31.35 & 27.77 & 26.02 & 27.18 \\
Y (2010) $(\mathrm{km})$ & 39.64 & 39.25 & 34.88 & 30.99 & 30.18 & 31.21 & 35.54 & 38.46 \\
Urban Land (2020) $\left(\mathrm{km}^{2}\right)$ & 58.98 & 51.39 & 73.36 & 80.86 & 61.82 & 63.14 & 65.71 & 64.48 \\
\hline
\end{tabular}




\section{Continued}

\begin{tabular}{lcccccccc}
\hline $\mathrm{X}(2020)(\mathrm{km})$ & 31.61 & 35.29 & 39.56 & 38.28 & 30.90 & 26.83 & 25.46 & 27.09 \\
$\mathrm{Y}(2020)(\mathrm{km})$ & 40.37 & 39.82 & 33.63 & 30.80 & 29.22 & 30.16 & 34.85 & 38.83 \\
$\mathrm{D}(\mathrm{m})$ & 755.49 & 581.34 & 1821.85 & 1749.191057 .33 & 1407.12 & 885.96 & 383.91 \\
$\mathrm{~V}(\mathrm{~m} / \mathrm{a})$ & 75.55 & 58.13 & 182.19 & 174.92 & 105.73 & 140.71 & 88.60 & 38.39 \\
Azimuth $\left(\theta^{\circ}\right)$ & 15.35 & 14.48 & 133.45 & 96.24 & 205.19 & 221.90 & 219.12 & 346.81 \\
Compaction Index & 0.44 & 0.42 & 0.51 & 0.45 & 0.26 & 0.32 & 0.35 & 0.47 \\
Expansion Rate $\left(\mathrm{km}^{2} / \mathrm{a}\right)$ & 1.76 & 1.36 & 3.39 & 3.85 & 2.15 & 2.31 & 1.44 & 1.21 \\
Expand Intensity Index & 4.25 & 3.59 & 8.57 & 9.11 & 5.32 & 5.79 & 2.82 & 2.31
\end{tabular}

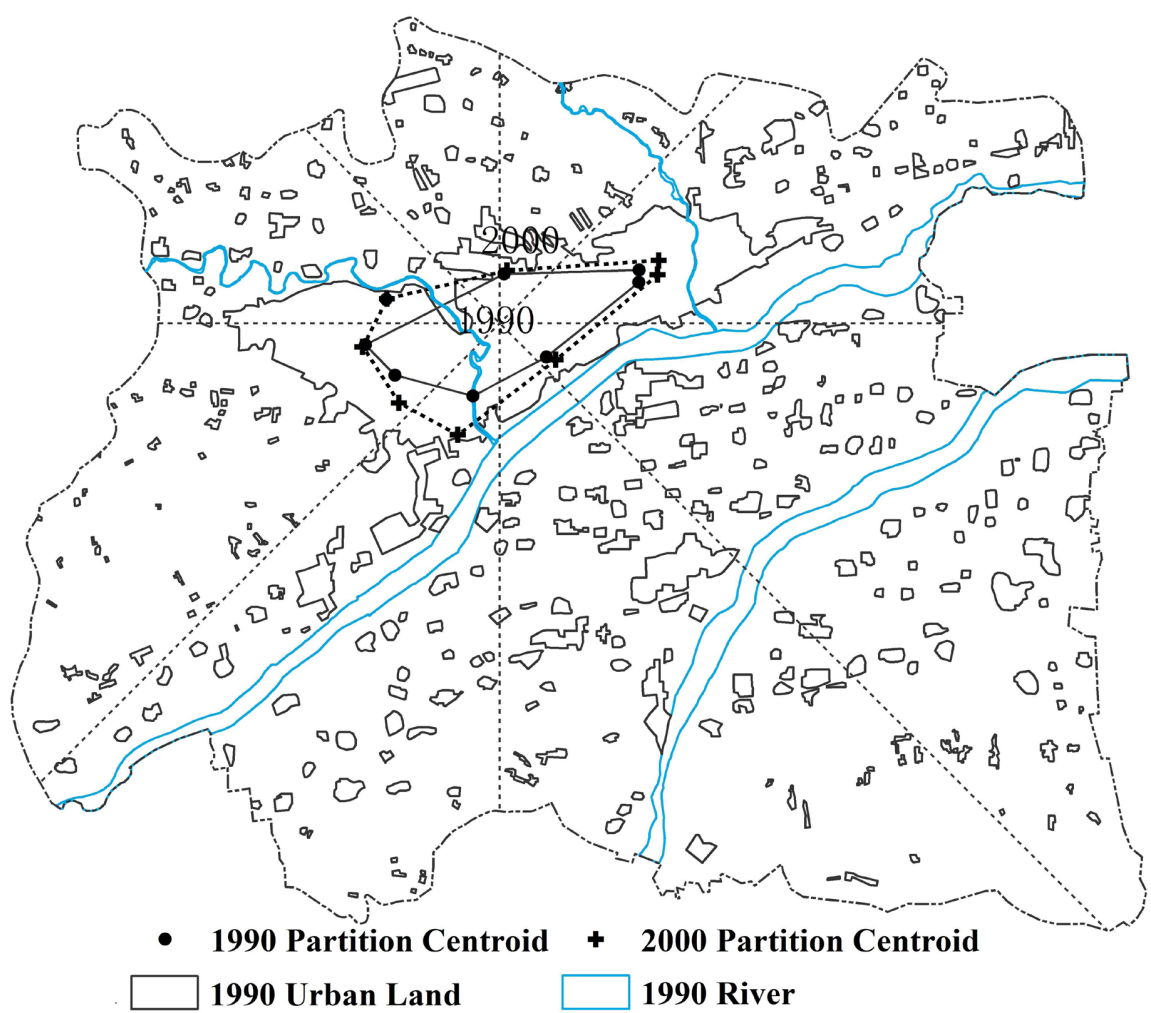

Figure 7. Luoyang urban land partition centroid in 2000.

lowest is in NN orientation, which is only $8.84 \%$ of SS orientation and $7.51 \%$ of SW orientation. The urban expansion area, expansion intensity and centroid migration distance are basically coordinated, indicating that the urban expansion mainly focuses on external expansion. There are also some differences, SS orientation and SW orientation have the highest urban expansion intensity, with the expansion directions respectively $201.13^{\circ}$ and $171.55^{\circ}$, their values are much higher than the other six orientation. The smallest values are in WW orientation and $\mathrm{WN}$ orientation, and their values are less than one fifth of the value in the maximum orientation. Compared with the other six orientations, the expansion intensity and centroid migration in ES orientation and EE orientation are inconsistent, indicating that in addition to outward expansion, internal filling is also 
one of the main factors of regional expansion in the two orientations.

Compared with the urban land centroid in 2000 (Table 4, Figure 8), Due to the reduction of the zoning, the urban space compaction of all zones have increased, the urban space compaction in the three orientations, as WW orientation, NW orientation and SW orientation, reach more than 2 times of that of the whole urban, these values in ES orientation and $\mathrm{NN}$ orientation are very small, less than 0.25 , indicating that the dispersion of urban land distribution is mainly caused by these two directions. The largest of urban expansion area and expansion intensity are in ES orientation and SS orientation, making the regional urban land centroids moves 599.14 meters and 355.01 meters annually along the directions of $141.92^{\circ}$ and $154.17^{\circ}$ respectively, the annual expansion area reaches more than $5 \mathrm{~km}^{2}$. The lowest is in NE orientation and NN orientation, the annual expansion area is less than $1 \mathrm{~km}^{2}$. The urban expansion area, expansion intensity and centroid migration distance are basically coordinated, indicating that the city mainly expands outward, but there are also some differences. There are some inconsistency between the expansion intensity and centroid migration in WN orientation and NN orientation, as well as SW orientation and EE orientation, where the expansion intensity of the former is greater than the latter, but the expansion area and centroid migration distance are less than the former, which may be related to their small base period area.

Compared with the urban land centroid in 2010 (Table 5, Figure 9), Due to the reduction of the zoning, except for SS orientation, the urban space compaction

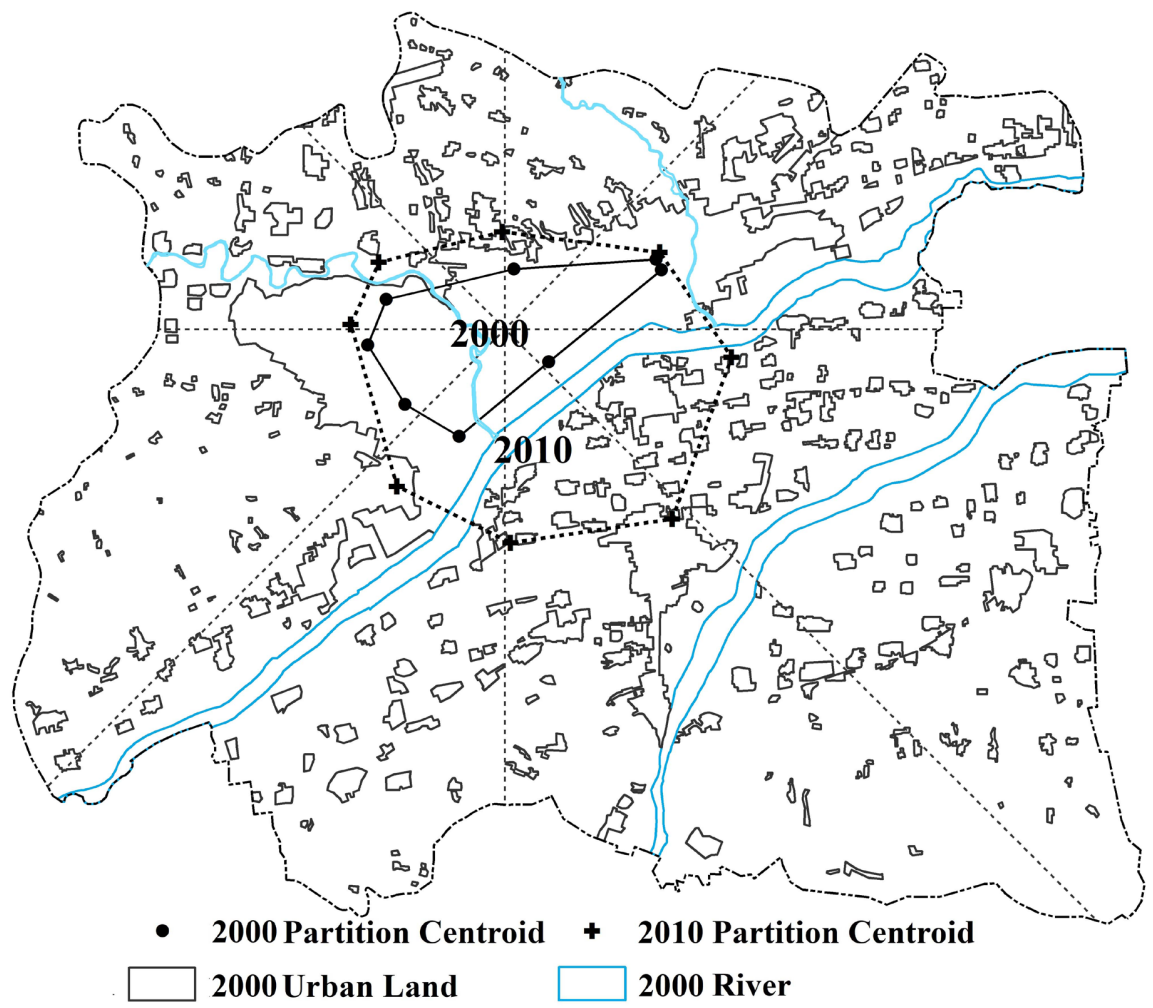

Figure 8. Luoyang urban land partition centroid in 2010. 


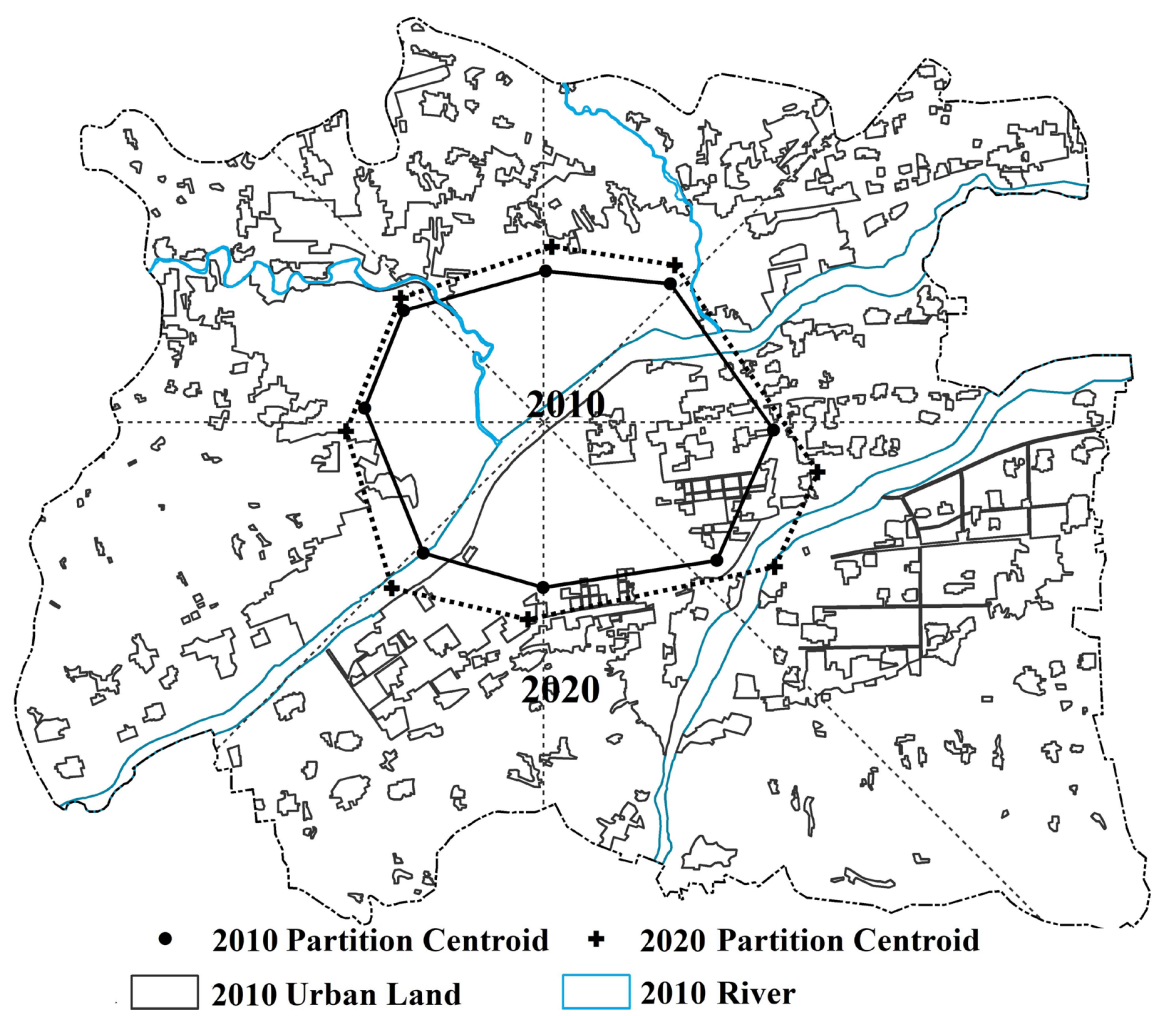

Figure 9. Luoyang urban land partition centroid in 2020.

of all other zones are higher than the overall urban space compaction. In SS orientation, the urban space compaction is less than the urban space compaction, which may be caused by the lack of comprehensive filling in Luonan area and the poor filling performance of the road network in Yibin new area. The largest of urban expansion area and expansion intensity are in EE orientation and NE orientation, in where the regional urban land centroids moves 182.19 meters and 174.92 meters annually along the directions of $113.45^{\circ}$ and $96.24^{\circ}$ respectively, with the annual expansion area $1.21 \mathrm{~km}^{2}$ and $1.36 \mathrm{~km}^{2}$ respectively. The urban expansion area, expansion intensity and centroid migration distance are basically coordinated, indicating that the urban is mainly outward expansion, but there are also some differences, the expansion intensity in WW orientation, NE orientation and NN orientation increase gradually, but the migration rates of centroid decrease gradually, which may be related to the difference of their base period area.

\section{Conclusion}

On the whole, the urban space compaction of Luoyang is relatively poor. Before 2000, due to the influence of topographic factors, the urban land expansion is mainly in the narrow strip in the north of Luo River and the south of Mang Mountains, and the urban space compaction gradually decreases. From 2000 to 2010, the urban crosses Luo River and strides over Sui and Tang Dynasties remain to the south, the urban framework gradually is expanded, but the filling 
effect is very poor, the urban space compaction further declines. From 2010 to 2020, with the gradual filling of the framework in Luonan New District, the urban space compaction returns to the level of 1990, but with the construction of the framework of Yibin New District, the urban space compaction is greatly pulled down.

From the perspective of expansion area, rate and intensity, in the past 30 years, the urban land expansion in Luoyang is mainly rapid expansion type and high-speed expansion type, and the built-up area expands by 3.76 times. Before 2000, the urban space expansion in Luoyang is mainly filling the built-up area and natural expansion to outward. From 2000 to 2010, in the early stage, the urban framework has been enlarged, and the urban area is expanded rapidly. In the later stage, the urban construction mainly fills the enlarged framework. From 2010 to 2020, the urban land expansion in Luoyang belongs to the high-speed expansion type. On the basis of filling the expanded urban framework in the previous period, it continues to enlarge the urban framework, the influence of urban natural growth factor is very little.

The urban land centroid gradually migrates to the southeast with the azimuth of $151.47^{\circ}$ and the rate of $138.29 \mathrm{~m} / \mathrm{a}$. The migration rate in the second period is the fastest. From the perspective of expansion orientation, in the first period, the urban construction expands along the azimuth of $201.13^{\circ}$ to SS. The expansion rate in northward is the slowest, in where the expansion area and intensity are only $17.19 \%$ and $34.96 \%$ of that in southward. Compared with the urban land centroid in 2000, in the second period, the urban land is mainly expanded to ES and SS, along the azimuths of $141.92^{\circ}$ and $154.17^{\circ}$, and the rates of $599.14 \mathrm{~m} / \mathrm{a}$ and $355.01 \mathrm{~m} / \mathrm{a}$ respectively, and their annual expansion area reaches more than $5 \mathrm{~km}^{2}$. In the third period, the urban land is mainly expanded in the orientations of ES and EE. The zoning centroid moves outward at an average annual rate of $174.92 \mathrm{~m}$ and $182.19 \mathrm{~m}$ along the azimuth angles of $96.24^{\circ}$ and $133.45^{\circ}$ respectively.

\section{Conflicts of Interest}

The authors declare no conflicts of interest regarding the publication of this paper.

\section{References}

Cai, H. P. (2013). Exploration of Green Space System Planning with Urban Historical and Cultural Characteristics: A Case Study in Luoyang City. Urban Development Studies, 20, 34-40.

Chang, B. R., \& Li, R. D. (2017). A Study of Remote Sensing Monitoring and Spatial Variation of Construction Land Expansion in Wuhan City. Remote Sensing for Land \& Resources, 29, 118-123.

Ge, Q. S., Zhao, M. C., Zheng, J. Y. (2000). Land Use Change of China during the 20th Century. Acta Geographica Sinica, 55, 698-706.

Geng, T. W., Mao, Y. Q., Li, J. Q. et al. (2019). Spatio-Temporal Characteristics and 
Driving Mechanism of Xi'an Urban Expansion. Economic Geography, 39, 62-70.

Huang, M. Y., Yue, W. Z., \& He, X. (2018). Decoupling Relationship between Urban Expansion and Economic Growth and Its Spatial Heterogeneity in the Yangtze Economic Belt. Journal of Natural Resources, 33, 219-232.

Li, D. R., Yu, H. R., \& Li, X. (2017). The Spatial-Temporal Pattern Analysis of City Development in Countries along the Belt and Road Initiative Based on Nighttime Light Data. Geomatics and Information Science of Wuhan University, 42, 711-720.

Liu, D. L., \& Song, K. Y. (1997). Luoyang Urban Chronicles (Urban Construction Chronicles). Zhongzhou Ancient Books Publishing House.

Lu, S. J. (2020). Characteristics and Driving Mechanism of Urban Space Expansion in Urumqi. Geomatics and Information Science of Wuhan University.

Tang, X. L., Yang, Q. L., Jiang, J. et al. (2017). Urban Spatial Expansion and Its Influence Factors Based on RS/GIS: A Case Study in Changsha. Economic Geography, 3, 81-85.

Wang, J., Xiu, C. L., \& Wei, Z. (2014). Dynamic Mechanism Analysis to Urban Spatial Expansion: Taking Shenyang City for Example. Urban Problems, 10, 29-35.

Xiong, H., Zheng, B. H., \& Jia, L. (2016). Urban Spatial Expansion in China under the Interaction between the Driving Force and the Restriction. Economic Geography, 36, 82-88.

Yan, M., \& Huang, J. C. (2013). Review on the Research of Urban Spatial Expansion. Progress in Geography, 7, 1039-1050.

Yu, Y. X., \& Chen, P. X. (2020). Monitoring and Analysis of Spatial Pattern Change of Urban Expansion in Beijing. Bulletin of Surveying and Mapping, 11, 132-136.

Zhang, K. G., Ba, M. T., \& Meng, H. L. (2017). Spatial-Temporal Characteristics of Henan Highway Traffic Network Accessibility and Its Evolution Pattern. Science of Surveying and Mapping, 32, 87-92.

Zhao, Y. R., Zou, Z. L., Zhang, Z. P., et al. (2019). The Relationship Analysis of Urban Expansion Types and Changes in Ecological Landscape Types Based on LEI and MSPA in the City of Nanchang. Journal of Natural Resources, 34, 732-744.

https://doi.org/10.31497/zrzyxb.20190405 